\title{
Tracing Russell's Views on the Relationship between Culture and Science as Intrinsically Linked through the Method of Analysis
}

\author{
Jahnabi Deka *
}

\section{Abstract}

Bertrand Russell, while expressing his deep concern for a prevailing negligence about an intrinsic aspect of science, which he terms culture, opines that culture is not to be understood as something divorced from science. His demarcation of old culture from young culture; and his claim that it is the young culture which is responsible for valuing science for its usefulness rather than its intrinsic aspect, i.e., prepares the stage for arguing in favour of endorsement of cultural intrinsicality of science. The paper argues that viewed from Russell's perspective, understanding culture as something unrelated to science will be a mistake, because it will carry a message to the mankind which is detrimental to the entire fabric of social cohesion. The paper focuses on the inculcation of scientific habit, an intrinsic aspect of science, as culture. While doing so, the paper intends to stress on the point that the scientific habit, which is linked to the Russellian method of analysis, common to both science and philosophy, plays a significant role in enabling one to focus on the cultural aspect of science. Analysis, in the province of philosophy, is used by Russell primarily to analyze language.

Keywords: Bertrand Russell, Intrinsic Aspect of science, Culture, Scientific Habit, Analysis, Language

* Department of Philosophy, Gauhati University, Guwahati, Assam, India; jahnabideka@gmail.com 


\section{Introduction}

Bertrand Russell (1872-1970), while expressing his deep concern for a prevailing negligence about an intrinsic aspect of science, which he terms culture, writes in the following words: "In my own country, and to a lesser degree in other countries of the West, "culture" is viewed mainly, by an unfortunate impoverishment of the Renaissance tradition, as something concerned primarily with literature, history and art. A man is not considered uneducated if he knows nothing of the contributions of Galileo, Descartes and their successors" (Russell, 1958). These words of Russell suggest that science cannot be considered as being devoid of culture; or to change the figure of speech, culture is not to be considered as that which cannot be comprehended in the context of science. Science can be understood from different perspectives, e.g., scientific knowledge of science is the habit of nurturing scientific habit towards life and world; on the other hand, scientific technique through which the material progress of the world has come into being is another aspect of science. While scientific knowledge possesses value independent of the narrow utility of science, the scientific technique is exclusively concerned with the usefulness of science. Russell observes that a tendency to appreciate science as a technique rather than as knowledge has become a practice in the society due to which he regretfully utters: “...the intrinsically valuable aspects of science tend to be sacrificed to the merely useful, and little attempt is made to preserve that leisurely systematic survey by which the finer quality of mind is formed and nourished"(Russell, 2004, p. 27). What Russell asserts by these words is that the cultural aspect of science is necessarily associated with the formation of finer quality of the mind, and culture understood in this sense is not compatible with the merely useful aspect of science. One major concern of the present paper therefore is to enquire into Russell's concept of culture which is understandable as an intrinsic aspect of science.

In the Russellian framework, the backbone of the cultural value of science is its method of analysis since Russell emphasises that it is through this method, the scientific habit of looking at the world can be inculcated. This means that the scientific habit is the chief 
component to weigh the cultural value of science in the Russellian discourse. Russell claims that scientific habit can be transferred to philosophy, and the possibility of this transferability indicates that the habit is common to both the provinces of science and philosophy. In the province of philosophy, Russell's method of analysis is primarily a method of analysis of language, which is spirited by scientific habit. As the inculcation of scientific habit and method of analysis of language are inseparably connected; and scientific habit is being viewed by Russell as a culture of science, the paper attempts to establish a link between analysis as a methodological device which is used in the analysis of language with that of the cultural aspect of science.

The paper argues that to understand culture as something unrelated to science will be a mistake, because it will carry a message to the mankind which will be detrimental to the entire fabric of social cohesion; and it will deteriorate the progression of mankind. While doing so, the paper devotes a part to explicate the point that analysis as a device of methodological commonality between science and philosophy plays a significant role in enabling us to focus on the cultural aspect of science. To proceed with the argument, the present paper has been divided into the following sections. The section Analysis as a Method, a brief account of Russell's understanding of the term Analysis has been put forth. However, the account is restricted to the core point of the method, i.e., the scientific spirit of the method. In the second section Science as Culture: Old and Young Cultures, a Russellian account of old culture and young culture has been put forward to decipher societal tendency behind appreciation of the extrinsic value rather than the intrinsic value of science. Here, Russell's Liberal Decalogue ${ }^{1}$ in the form of Ten Commandments are cited as possible pathways for imbibing scientific habit or in other words culture of science. In the third section, Philosophic Uncertainty, a discussion has been presented to show how the uncertainty of philosophy is connected to the cultural value of science. The last section is the conclusion. 


\section{Analysis as a Method}

As regards to the methods of philosophical investigations, Russell considers analysis to be the 'strongest and most unshakable prejudice' (Russell, 1997, p. 99). As Russell understood philosophy in the sense of analysis, philosophers like Elizabeth Eames remark that to understand Russell's method of analysis is to understand his philosophy (Eames, 1969, p.56). His method of analysis is primarily a logico-mathematical method in that he uses mathematical logic to dissect philosophical problems. By applying this method he sought to remove ambiguities associated with ordinary language. This is the reason why Russell reconstructed ordinary language thereby formulating symbolic or ideal language for philosophical purposes. This means that by preferring ideal language over ordinary language in analysing philosophical issues, Russell sought to minimise the risk of error in philosophy. A distinctive example of his application of analysis within the sphere of technical philosophy is his concept of definite descriptions ${ }^{2}$. His theory of definite descriptions shows how certain phrases of ordinary language can be removed with the help of quantificational logic (a part of symbolic logic) which brings about clarity to ordinary language. In short, analysis is being used by Russell to purify language and to bring about the non-linguistic aspect of nature. Thus, the chief motive behind the application of analysis is to bring about clarity to the concepts analysed. Russell compares the method of analysis to the process of seeing something through a microscope after seeing it through naked eyes, e.g., bacilli in impure water are not visible through the naked eyes, unless it is viewed through the microscope. He defends his method and says: "There are many who decry analysis, but it has seemed to me evident, as in the case of the impure water, that analysis gives new knowledge without destroying any of the previously existing knowledge. This applies not only to the structure of physical things, but quite as much to concepts"(Russell, 1997, p. 98). That is, with the help of the method of analysis concepts can also be made clearer and more precise. But clarity and precision here cannot be understood to be equated with absolute certainty. It only means to be able to state something with a scientific outlook. Explaining the crux of the scientific outlook, Russell says that "The kernel of the 
scientific outlook is the refusal to regard our own desires, tastes, and interest as affording a key to the understanding of the world"(Russell, 2004, p. 33).

Method of analysis is an intellectual endeavour because it demands an impersonal outlook toward life, and it is only through the scientific habit of mind, an impersonal outlook can be generated. The application of the method requires careful veracity on the applicant's part to bring about more clarity to the concepts. While reflecting on the habit of careful veracity, Russell says that "The habit of careful veracity acquired in the practice of this philosophical method can be extended to the whole sphere of human activity, producing, wherever it exists, a lessening of fanaticism with an increasing capacity of sympathy and mutual understanding"(Russell, 2002, p. 789). Careful veracity is nothing but the scientifically spirited mind which has the incredible capability to dissect any issue by setting aside personal bias and prejudices.

By culture, Russell means "a system of beliefs, or at least of habits, an artistic or intellectual tradition, and ways of making social coherence possible" (Russell, 2010, pp. 132-133). Within the Russellian paradigm, therefore, scientific habit, as a carefully driven intellectual habit, which is intrinsically present in science, and which is extensible to the entire human activity, qualifies to be signified as a cultural aspect of science. Culture, understood as an intrinsic aspect of science stimulates one's scientific habit of thinking, and enables one to free oneself from personal biases and prejudices. We may now turn our attention to understand Russell's understanding of science as culture.

\section{Science as Culture: Old and Young Cultures}

"Science", Russell writes in the introduction to his book The Scientific Outlook, "is primarily knowledge; by convention it is knowledge of a certain kind, the kind, namely which seeks general laws connecting a number of particular facts"(Russell, 1954, p. 19). As Russell says that science as a technique is being admired in the contemporary society rather than science as knowledge, he mentions 
the reason for such admiration too. He says that science as a technique has the power to manipulate nature which has helped it receive more social importance than art. He further says that admiration of science as a technique rather than as knowledge is due to young culture. Mentioning two sorts of culture as old and young, in his book Fact and Fiction, and by demarcating between the two, Russell opines that the "The new culture is that of science-not, mainly, of science as knowledge, but, rather, of science as technique" (Russell, 2010, p. 133). The old culture, for Russell, is that which lays "stress upon what, in a certain sense, may be called play"(Russell, 2010, p.137), while the new culture emphasizes on work. Russell uses the word 'play' here to mean "whatever is not designed for practical utility" (Russell, 2010, p.137). Under the word play Russell includes art, literature and contemplative philosophy, and the pursuit of knowledge "when not subservient to technique"(Russell, 2010, p.137). As the word play, in the Russellian discourse, indicates knowledge which is not subservient to technique, the word play, therefore, acquires a unique import in his use, i.e., to value intrinsic value of knowledge without considering its practical utility. Russell cites examples of Greeks who pursued knowledge in mathematics and astronomy with the sole exception of Archemedes, for its own sake, and not for usefulness of knowledge. Based on Russell's argument that old culture valued knowledge for its own sake, and the new culture values knowledge for its narrow utility, it can be held therefore that the oft-neglected cultural aspect of science is primarily due to young culture. Nevertheless, nowhere Russell says that the extrinsic value, i.e. utility of science is not to be valued anymore, because he is well aware of the effects of scientific technique in the society. Russell's point here can be substantiated more clearly with the help of his own words: "Science as a technique has a future consequence of which the implications are not yet fully evident, namely, that it makes possible, and even necessary, new forms of human society"(Russell, 1954, p.11). However, to ignore the intrinsic aspect of science means to ignore the kernel of scientific outlook being mentioned above.

Now, the question is - why to worth the intrinsic aspect of science at all according to Russell? Narrating the scientific attitude of mind 
(or we may say, narrating the intrinsic aspect of science), Russell writes:

"The scientific attitude of mind involves a sweeping away of all other desires in the interests of the desire to know -it involves suppression of hopes and fears, loves and hates, and the whole subjective emotional life, until we become subdued to the material, able to see it frankly, without preconceptions, without bias without any wish except to see it as it is, and without any belief that what it is must be determined by some relation, positive or negative, to what we should like it to be, or to what we can easily imagine it to be" (Russell, 2004, p. 34)

This intrinsic value of science, which is carried out for the sake of desiring to know, i.e., to know something for its own sake, as mentioned above, is the culture of speculating something in a disinterested fashion. Such disinterested speculation, as is aimed at knowing something for its own sake, is a passion for truth to be approached impersonally. This impersonal outlook is the outlook which is associated with the method of analysis mentioned above. Once the truth is approached impersonally, Russell says, there arises "desire for a larger life and wider interests, for an escape from private circumstances, ..."(Russell, 2004, p. 34). Scientific attitude thus broadens one's horizon of speculation in that it capacitates someone to rise above one's interests and to live for a larger life. Quest for a larger life is a necessary prerequisite for bringing about social coherence because it is only with the help of this quest one can get rid of narrow hopes and fears thereby can contribute to the cause of social cohesion.

It would be worth citing at this point Russell's Ten Commandments known as Liberal Decalogue which summarily represents his liberal outlook. The outlook is said to be liberal because it is inspired by the nourishment of the scientific habit of mind. This liberal outlook (Ten Commandments of Russell) encourages one to delve deeper into the adoption of certain ways so that one must not aspire to be absolutely certain of anything. It also enables one to be able to keep sufficient room for further analysis on any given issue. In other words, via this outlook, one keeps enough room for revision and 
rectification of one's earlier thesis. To quote Russell: “The Ten Commandments that, as a teacher, I should wish to promulgate, might be set forth as follows:

1. Do not feel absolutely certain of anything.

2. Do not think it worthwhile to proceed by concealing evidence, for the evidence is sure to come to light.

3. Never try to discourage thinking for you are sure to succeed.

4. When you meet with opposition, even if it should be from your husband or your children, endeavour to overcome it by argument and not by authority, for a victory dependent upon authority is unreal and illusory.

5. Have no respect for the authority of others, for there are always contrary authorities to be found.

6. Do not use power to suppress opinions you think pernicious, for if you do the opinions will suppress you.

7. Do not fear to be eccentric in opinion, for every opinion now accepted was once eccentric.

8. Find more pleasure in intelligent dissent than in passive agreement, for, if you value intelligence as you should, the former implies a deeper agreement than the latter.

9. Be scrupulously truthful, even if the truth is inconvenient, for it is more inconvenient when you try to conceal it.

10. Do not feel envious of the happiness of those who live in a fool's paradise, for only a fool will think that it is happiness" (Russell, 1998, p. 553-554)

These Commandments can be understood as Russellian pathways which may function as a set of links between ones' scientific outlook or liberal outlook and philosophical uncertainty. However, the word uncertainty here is not to mean scepticism-uncertainty here is used in a special sense which means that one is supposed to be tentative about one's own thesis, because on the availability of new evidence one may have to rectify and revise one's original thesis. This 
tentativeness, as it is scientifically spirited, is an integral component of culture. The discussion in the section below is being targeted to show the link of philosophic uncertainty with that of cultural intrinsicality of science.

\section{Philosophic Uncertainty}

In his book Unpopular Essays, Russell opines that ever since civilized communities are confronted with problems of two different kinds: first, there arises the problem of mastering natural forces, to acquire knowledge and skill which is required to produce tools and weapons, and to know how Nature can be utilised to produce useful plants and animals. This problem, he says, in the modern times, has been sought to be tackled by science and scientific technique. And Russell says that science has been successful in tackling the problem too. Second, there arises the problem of utilising our command over the forces of Nature in the best possible way. Here, Russell includes burning issues as democracy versus dictatorship, capitalism versus socialism, international government versus international anarchy, free speculation versus authoritarian dogma. Russell considers the second problem to be rather grave, and to deal with these problems, requires, he says, "a wide survey of human life, in the past as well as in the present, and an appreciation of the sources of misery or contentment as they appear in history (Russell, 1935, p. 35). In support of his statement, Russell puts forward one example of the production of an atom bomb. Atom bomb, he says, was produced by the combination of scientific genius and technical skill, but mankind got scared of hearing the name of atom bomb because of the devastation and traumatic effects made by the atom bombs during world wars. Hence, Russell concludes that something more than scientific technique has to be learnt to get to know how to best utilise our command over Nature. Scientific skill is necessarily needed to complete the task. But such knowledge has to be accompanied by philosophic wisdom. By wisdom, Russell means "a right conception of the ends of life" (Russell, 1954, p. 12). And the ends of life nevertheless are to be carried forward with a scientific habit of disinterested pursuit for truth. 
Russell by referring to the meaning of 'Philosophy' as 'love of wisdom' says that men are to acquire wisdom "if the new powers invented by technicians, and handed over by them to be wielded by ordinary men and women, are not to plunge mankind into an appalling cataclysm" (Russell, 1921, p. 36). Now, how does wisdom of philosophy in the said context capacitate mankind to save itself from cataclysm just mentioned? Viewed from the Russellian perspective, it can be said that it is nothing but uncertainty found in philosophy which can save humanity from any cataclysm.

While speaking of philosophic uncertainty, Russell refers to the close relationship between science and philosophy. For example, he says that astronomy and psychology which were previously included in philosophy got branched off from philosophy now because "as soon as definite knowledge concerning any subject becomes possible, this subject ceases to be called philosophy, and becomes a separate science"(Russell, 1999, p. 90). This means that the moment any definite answer can be provided concerning any question, it ceases to be a philosophical question, and the question is placed in the sciences. This further means that philosophy is unable to provide any definite answer to any question. This causes Russell to remark that "The value of philosophy is, in fact, to be sought largely in its very uncertainty"(Russell, 1999, p. 91). Dwelling on the advantage of such uncertainty he writes: "...while diminishing our feeling of certainty as to what they may be; it removes the somewhat arrogant dogmatism of those who have never travelled into the region of liberating doubt, and it keeps alive our sense of wonder by showing familiar things in an unfamiliar aspect"(Russell, 1999, p. 91). For a man of philosophy, therefore, the world ceases to become definite, finite and obvious. This means that philosophy incites seed of wonder which kills the attitude of dogmatism in men, and suggests many possibilities for widening men's contemplative thought. By widening possibilities philosophy enriches our 'intellectual imagination' (Russell, 1999, p.93). But intellectual imagination is not something fanciful. Rather, in Russell's philosophical framework, such imagination has the greatest capacity to make one capable of expanding one's speculative interest in life and the world. To expand one's speculative interest means to desire to know the world. This again 
means that by expanding one's speculative interest one goes beyond what is personal to conceive the universe as a whole. Philosophic speculation by aiming at the disinterested search for truth never places any limits to the pursuit of truth. As Russell rightly states: "When any limits are placed, consciously or unconsciously, upon the pursuit of truth, philosophy becomes paralysed by fear, and the ground is prepared for a government censorship punishing those who utter 'dangerous thoughts' - in fact, the philosopher has already placed such a censorship over his own investigations"(Russell, 2002, p. 788). That is, not to put any limit to one's pursuit of truth is a philosophical endeavour. This endeavour rests on one's respect for philosophic uncertainty which is not possible to attain unless one is methodically spirited by analysis.

\section{Conclusion}

The ongoing discussion in the present paper sets the stage for removal of the prevailing misconception in the society as has been pointed out by Russell, i.e., science is divorced from culture. It shows why a passion for disinterested speculation deserves to be called a cultural aspect of science -- as because, such passion in the Russellian discourse opportunes mankind to inculcate a habit of desiring to know which means to know something for its own sake. Such a desire to know something for its own sake enables one to approach truth independently of one's interests, biases etc. However, it cannot be denied that this journey of disinterested speculation is tough though not impossible. The journey has to be processed intellectually as desiring to know something for its own sake is an intellectual journey. Russell's sincere submission that the growing attention to the scientific technique rather than scientific knowledge brings to light an underlying tension as regards to the value of science, i.e., it throws light on the tension between intrinsic value and the extrinsic value of science. His remark that the intrinsically valuable aspect of science is being tended to be sacrificed to the usefulness of science, i.e., to the extrinsic value of science is to be noted worthily to bring to light one significant reason responsible for the emergence of the mentioned sacrifice- 
the reason which is related to his concept of old culture and the young culture. This again means that culture is not be conceived in a narrow utilitarian sense which means that it is not to be understood as a weapon to bring about useful results where the term useful is comprehended as something which is related to productions of material utility only.

The cultural value, which is an intrinsic value of science in the Russellian parlance, is methodologically linked to analysis. As such, the cultural aspect of science can be judiciously said to be an aspect which possesses methodological value too. As the method of analysis is common to both philosophical discourse, and to science; by tracing the methodological commonality, a relation between value of philosophy, i.e., philosophic uncertainty and the intrinsic value of science, i.e., culture can be discerned in the Russellian discourse.

It also follows from the ongoing discussion that careful veracity is Russell's another significant highlight in the context of understanding culture as an intrinsic aspect of science. Careful veracity, as it relies on the available evidence present as of now, and welcomes new evidence; such veracity allows one to throw new light on one's thesis at hand. This tentative veracity is the methodological aspect of Russell's analysis. Russell, by holding the view that the habit of careful veracity attained in the process of the philosophical method of analysis, which is extensible to the whole sphere of human activity increases sympathy and mutual understanding; indeed refers to the value of tentative veracity. In short, this is what the scientific spirit is. Relentless strive toward inculcation of this tentative veracity, can therefore be cited as an endeavour-philosophic wisdom, which can perhaps be attempted to be seen as an aspect equal to that of the cultural aspect of science for Russell. In this regard, his Ten Commandments can be said to have paved the way for initiating a programme which will ultimately enable one to adopt liberal outlook-or in the context of science, it is culture. 


\section{End Notes}

1 It first appeared at the end of his article 'The Best Answer to Fanaticism-Liberalism', in The New York Times Magazine, December 16, 1951.

2 See, Russell, B. (2004), On Denoting. in Marsh, Robert Charles (Ed.), Logic and Knowledge, London and New York.

\section{References}

Eames, E. R. (1969). Bertrand Russell's theory of knowledge, George Allen and Unwin Ltd.

Russell, B. (1921). Unpopular essays. George Allen and Unwin Ltd.

Russell, B. (1954). The scientific outlook. George Allen and Unwin Ltd.

Russell, B. (1958). The divorce of science and culture. An address delivered on January 28, 1958 on receiving Kalinga Prize for the popularization of Science. Retrieved from https://users.drew.edu

Russell, B. (1997). My philosophical development. Routledge: London and New York.

Russell, B. (1998). Autobiography. Routledge: London and New York.

Russell, B. (1999). The Problems of philosophy. Oxford University Press.

Russell, B. (2002). History of western philosophy. Routledge: London and New York.

Russell, B. (2004). Mysticism and logic. Dover Publications, Inc: Mineola, New York.

Russell, B. (2010). Fact and fiction. Routledge: London and New York. 